\title{
OS LIMITES DA DESCONSIDERAÇÃO DA PERSONALIDADE JURÍDICA
}

\author{
THE LIMITS OF DISREGARD DOCTRINE
}

\author{
Gustavo Ribeiro Rocha6
}

Artigo recebido em: 14/11/2018.

Artigo aprovado em: 05/12/2018.

Resumo: o presente trabalho apresenta, a partir da Lei, da doutrina e jurisprudência nacionais, algumas importantes características do instituto da desconsideração da personalidade jurídica no Direito brasileiro, especialmente em seu aspecto material, visando à sua adequada compreensão, para aplicação casuística. Para tanto, o presente trabalho propõe a observação das dificuldades em se chegar a um conceito objetivo, bem como os desafios de diferenciá-la de outras medidas jurídicas, tais como a dissolução da sociedade, a responsabilidade ilimitada de sócio e a responsabilidade de administrador por atos culposos ou dolosos, insolvência ou inexistência de bens, até sua adequada aplicação em casos concretos. Com este trabalho espera-se contribuir para os estudos da teoria da desconsideração da personalidade jurídica e tratamentos mais adequados à sua aplicação no Direito brasileiro, a partir do texto legal, da doutrina e da jurisprudência nacionais, visando evitar sua inadequada aplicação, que pode levar ao seu uso abusivo e indiscriminado, que pode até mesmo levar tal instituto ao descrédito.

Palavras-chave: desconsideração; personalidade; jurídica; responsabilidade; ilimitada.

Abstract: The present study presents, from the Brazilian's Law, doctrine and jurisprudence, some important characteristics of disregard of legal personality in Brazil's Law, especially in its material aspect, aiming at their adequate understanding, for casuistic application. Therefore, this paper proposes the observation of the difficulties in reaching a objective concept, as well as and the challenges of differentiate from other institutes of Law, such as the dissolution of society, the partner's unlimited liability and the manager responsibility for wrongful or intentional acts, insolvency or lack of goods, until its proper application in concrete cases. With this work we hope to contribute to the studies and treatments most appropriate of disregard of legal personality in Brazil's Law, from the Brazilian's Law, doctrine and jurisprudence, in order to avoid its inadequate application, which can lead to abusive and indiscriminate use, which may even lead such an institute to discredit.

Keywords: disregard; legal; personality; unlimited; liability.

\section{INTRODUÇÃO}

A chamada desconsideração da personalidade jurídica visa tornar possível a superação momentânea da personalidade jurídica pelo juiz, para, pontual e episodicamente, combater a fraude e/ou o abuso

\footnotetext{
${ }^{6}$ Mestre em Direito de Empresa, Faculdade de Direito Milton Campos (2008). Especialista em Direito de Empresa, Centro de Atualização em Direito (2004). Bacharel em Direito, Faculdade de Direito Milton Campos (2003). Advogado (2003). Professor Universitário (2004)
} 
cometidos por um dos sócios ou pelos sócios, valendo-se da pessoa jurídica. Por outras palavras, a medida se mostra oportuna quando o sócio ou os sócios se valem da pessoa jurídica como escudo para cometer fraudes ou abusos.

Assim, quanto ocorrerem situações que autorizam tal desconsideração, o juiz poderá superar a existência da personalidade jurídica, como se ela não existe e, assim, naquele episódio, diante de certo contexto, responsabilizar quem, de fato, cometeu a fraude e/ou o abuso. Trata-se, portanto, de medida aguda, que deve ser utilizada com parcimônia, com critério, para que sua aplicação seja oportuna, tendo em vista que a partir da "autonomia patrimonial reconhecida às pessoas jurídicas, muitos sócios começaram a usálas como uma espécie de blindagem patrimonial para cometerem fraudes e abusos, afastando-se da responsabilidade” (OLIVEIRA, 2014, p. 187).

Em síntese, pois, deve-se pensar em desconsideração da personalidade jurídica como medida excepcional, e cogitar sua aplicação quando ocorrer abuso sustentado em dolo, fraude, desvio de finalidade ou confusão patrimonial, com a finalidade de prejudicar terceiros.

Porém, para melhor compreensão do instituto, mister notar, ab initio, que tal recurso excepcional ${ }^{7}$ não pode ser confundido com outras medidas ou institutos judiciais, v.g., dissolução da sociedade ou responsabilização de administrador, nem responsabilização de sócio em sociedade de responsabilidade ilimitada, muito menos com solução contra a insolvência ou inexistência de bens do devedor, conforme será diferenciado ao longo deste trabalho.

\section{A DESCONSIDERAÇÃO DA PERSONALIDADE JURÍDICA}

A partir da doutrina e jurisprudência pátrias, pode-se perceber que a desconsideração da personalidade jurídica pressupõe uma pessoa jurídica regular e a prática, por meio dela, de uma ilicitude.

Por isso, para pensarmos em personalidade jurídica, imperioso ter em mente o disposto no art. 45, do Código Civil, que dispõe, in verbis:

\footnotetext{
“Art. 45. Começa a existência legal das pessoas jurídicas de direito privado com a inscrição do ato constitutivo no respectivo registro, precedida, quando necessário, de autorização ou aprovação do Poder Executivo, averbando-se no registro todas as alterações por que passar o ato constitutivo.” grifo nosso.
}

\footnotetext{
7 "[... a desconsideração da personalidade jurídica é admitida em situações excepcionais, devendo as instâncias ordinárias, fundamentadamente, concluir pela ocorrência do desvio de sua finalidade ou confusão patrimonial desta com a de seus sócios, requisitos sem os quais a medida torna-se incabível" (STJ, 3 ${ }^{\mathrm{a}}$ T., REsp n. 1.311.857/RJ, Rel. Min. Nancy Andrighi, j. 13/5/2014, DJe 2/6/2014).
} 
Observada essa regra, as pessoas jurídicas passam a ter existência distinta da dos seus membros, o que pode justificar, casuisticamente, a desconsideração a personalidade jurídica, a partir, especialmente, do disposto no art. 50, do Código Civil, que dispõe, in verbis:

\begin{abstract}
“Art. 50. Em caso de abuso da personalidade jurídica, caracterizado pelo desvio de finalidade, ou pela confusão patrimonial, pode o juiz decidir, a requerimento da parte, ou do Ministério Público quando lhe couber intervir no processo, que os efeitos de certas e determinadas relações de obrigações sejam estendidos aos bens particulares dos administradores ou sócios da pessoa jurídica." - grifo nosso.
\end{abstract}

Vejamos a aplicação do referido artigo em casos concreto:

“[...] O legislador pátrio, no art. 50 do CC de 2002, adotou a teoria maior da desconsideração, que exige a demonstração da ocorrência de elemento objetivo relativo a qualquer um dos requisitos previstos na norma, caracterizadores de abuso da personalidade jurídica, como excesso de mandato, demonstração de desvio de finalidade (ato intencional dos sócios em fraudar terceiros com o uso abusivo da personalidade jurídica) ou a demonstração de confusão patrimonial (caracterizada pela inexistência, no campo dos fatos, de separação patrimonial entre o patrimônio da pessoa jurídica e dos sócios ou, ainda, dos haveres de diversas pessoas jurídicas." (STJ, 4ª T., Ag. no Resp. 347.476 DF, re. Min. Raul Araújo, j. 5/5/2016)

Resta claro, assim, que a personalidade jurídica não constitui um direito absoluto, vez que está sujeita à teoria da fraude contra credores e à teoria do abuso de direito. E justamente para combater a fraude e o abuso de direito é que surgiu a teoria ou doutrina da desconsideração, ou do superamento da personalidade jurídica. Para Ramos, isso evidencia "a clara finalidade de salvaguardar o princípio da autonomia patrimonial, evitando seu uso abusivo e deturpado" (RAMOS, 2012, p. 402).

Atualmente, tal teoria está definitivamente incorporada ao nosso Direito, conforme se vê, especialmente, a partir da leitura do art. 28, do Código de Proteção e Defesa do Consumidor ${ }^{8}$ (Lei n. 8.078, de $11 / 9 / 1990)^{9}$ e do já destacado art. 50, do Código Civil brasileiro, para os casos “de abuso da personalidade jurídica, caracterizado pelo desvio de finalidade, ou pela confusão patrimonial”. Além deles, observa-se o instituto no art. 34, da Lei n. $12.529 / 2011^{10}$, que trata sobre prevenção e repressão às infrações contra a ordem econômica, - apesar de misturar a desconsideração com responsabilidade ilimitada de sócio

\footnotetext{
${ }^{8}$ Oliveira explica que o Código de Defesa do Consumidor adotou a chamada teoria menor da desconsideração, tendo como suficiente a demonstração de prejuízo para embasar a desconsideração, sem análise do requisito subjetivo da fraude ou abuso de direito. In: OLIVEIRA, Júlio Moraes. Curso de direito do consumidor completo. Belo Horizonte: D’Plácido, p. 189/190, 2014.

9 "Art. 28. O juiz poderá desconsiderar a personalidade jurídica da sociedade quando, em detrimento do consumidor, houver abuso de direito, excesso de poder, infração da lei, fato ou ato ilícito ou violação dos estatutos ou contrato social. A desconsideração também será efetivada quando houver falência, estado de insolvência, encerramento ou inatividade da pessoa jurídica provocados por má administração."

10 “Art. 34. A personalidade jurídica do responsável por infração da ordem econômica poderá ser desconsiderada quando houver da parte deste abuso de direito, excesso de poder, infração da lei, fato ou ato ilícito ou violação dos estatutos ou contrato social. Parágrafo único. A desconsideração também será efetivada quando houver falência, estado de insolvência, encerramento ou inatividade da pessoa jurídica provocados por má administração.”
} 
ou responsabilidade de administrador, e com falência e insolvência - e do art. $4^{\text {o }}$, da Lei n. 9.605/1998 ${ }^{11}$, que trata de crimes ambientais.

Mas, é sempre oportuno ter em mente que tal instituto não deve ser entendido como um "cheque em branco aos credores supostamente prejudicados" (BARBOSA, 2017, p. 51-96), pois é instrumento excepcional, a partir do cumprimento de suas condições, "pautado pela necessidade de demonstração minimamente indiciária dos abusos perpetrados pelos sócios em detrimento ou sob o falso escudo formal da pessoa jurídica" (BARBOSA, 2017, p. 51-96), com o que estamos plenamente de acordo. Nesse sentido, atual e oportuna a ressalva expressa em recente julgado do Superior Tribunal de Justiça:

\begin{abstract}
"Para aplicação da teoria maior da desconsideração da personalidade jurídica (art. 50 do CC/2002), exige-se a comprovação de abuso, caracterizado pelo desvio de finalidade (ato intencional dos sócios com intuito de fraudar terceiros) ou confusão patrimonial, requisitos que não se presumem mesmo em casos de dissolução irregular ou de insolvência da sociedade empresária. (REsp 1.526.287/SP, Rel. Ministra Nancy Andrighi, Terceira Turma, DJe 26/5/2017; REsp 1.315.166/SP, Rel. Ministro Gurgel de aria, Primeira Turma, DJe 26/4/2017; e AgInt no AREsp 472.641/SP, Rel. Min. Raul Araújo, Quarta Turma, DJe 05/04/2017). [...] Afastada a preclusão indevidamente aplicada na origem, deve ser garantida aos sócios a possibilidade de produzirem prova apta, ao menos em tese, a demonstrar a ausência de conduta abusiva ou fraudulenta no uso da personalidade jurídica, sob pena de indevido cerceamento de defesa." (STJ, $3^{\mathrm{a}}$ T., Resp. n. 1.572.655RJ, Rel. Min. Ricardo Villas Bôas Cueva, j. 20/3/2018, DJe 26/03/2018) - grifo nosso.
\end{abstract}

Dessa maneira, conforme já expusemos em publicação anterior, verificado "o abuso ou a fraude por intermédio de uma pessoa jurídica, tem lugar, se limitada a responsabilidade de seus integrantes, a aplicação da doutrina do superamento da personalidade jurídica” (ROCHA; ROCHA FILHO, 2018, p. 378), visando atingir e responsabilizar, pessoalmente, o verdadeiro sujeito da violação, do abuso ou da fraude: um sócio minoritário, um administrador, um sócio controlador. Mas, conforme indicado alhures, por vezes a desconsideração é confundida com outras situações e institutos, conforme se vê da redação do art. 34, da Lei n. 12.529/2011, in verbis:

\footnotetext{
“Art. 34. A personalidade jurídica do responsável por infração da ordem econômica poderá ser desconsiderada quando houver da parte deste abuso de direito, excesso de poder, infração da lei, fato ou ato ilícito ou violação dos estatutos ou contrato social.
}

Parágrafo único. A desconsideração também será efetivada quando houver falência, estado de insolvência, encerramento ou inatividade da pessoa jurídica provocados por má administração.”

Vê-se que ao tratar sobre a prevenção e a repressão às infrações contra a ordem econômica, o legislador pátrio tratou da questão da fraude ou abuso, mas especialmente em seu parágrafo único, elenca outras hipóteses, de responsabilidade ilimitada de sócio ou responsabilidade de administrador, falência e

\footnotetext{
11 “Art. $4^{\circ}$ Poderá ser desconsiderada a pessoa jurídica sempre que sua personalidade for obstáculo ao ressarcimento de prejuízos causados à qualidade do meio ambiente."
} 
insolvência, como sendo também, hipóteses de desconsideração, o que entendemos inadequado, assim como Ramos, vez que "não condizem com as formulações doutrinárias que deram origem à disregard doctrine, prevendo a sua aplicação em casos para os quais o ordenamento jurídico já contém remédios eficientes" (RAMOS, 2012, p. 404), que são as situações relacionadas a excesso de poder, prática de ilicitude (violando a Lei ou o ato constitutivo), ou até mesmo dissolução de sociedade, conforme será exposto a seguir.

\subsection{A desconsideração da personalidade jurídica x responsabilidade ilimitada de sócio}

Além da importância da busca pelo conceito da desconsideração, especialmente a partir do disposto no art. 50, do Código Civil, outro importante cuidado é o de não confundir a situação do referido artigo com a eventual responsabilidade ilimitada que pode recair sobre um sócio, em razão do tipo societário que integra, vez que "quanto à responsabilidade dos sócios, as sociedades podem ser agrupadas em Limitadas, Ilimitadas e Mistas. Mas, atente-se bem: quanto à responsabilidade dos sócios" (ROCHA; ROCHA FILHO, 2018, p. 351), pois as sociedades sempre terão responsabilidade ilimitada por suas obrigações.

Dessa forma, em se tratando de sócio com responsabilidade ilimitada, que, por isso, também é responsável pelas obrigações sociais - v.g., sócios de uma sociedade em comum; ou sócio ostensivo, em uma sociedade em conta de participação -, não devemos pensar em desconsideração da personalidade jurídica para atingir o patrimônio particular do sócio, pois nesse caso os sócios são solidária e ilimitadamente responsáveis pelas obrigações sociais, sem necessidade de se lançar mão da desconsideração. Veja-se:

\footnotetext{
"Tratando-se de regra de exceção, de restrição ao princípio da autonomia patrimonial da pessoa jurídica, a interpretação que melhor se coaduna com o art. 50 do Código Civil é a que relega sua aplicação a casos extremos, em que a pessoa jurídica tenha sido instrumento para fins fraudulentos, configurado mediante o desvio da finalidade institucional ou a confusão patrimonial. 2. O encerramento das atividades ou dissolução, ainda que irregulares, da sociedade não são causas, por si só, para a desconsideração da personalidade jurídica, nos termos do Código Civil. 3. Embargos de divergência acolhidos." (STJ, 2 ${ }^{\mathrm{a}}$ Seção, EREsp 1.306.553/SC, Rel. Min. Maria Isabel Gallotti, j. 10/12/2014, DJe 12/12/2014) - grifo nosso.

"Consoante se observa nos autos, a decisão agravada adotou como tese a impossibilidade de
desconsideração da personalidade jurídica fundamentada unicamente na dissolução irregular do ente
coletivo. Nessa senda, o Superior Tribunal de Justiça sedimentou o entendimento de que, tratando-se
de relações jurídicas de natureza civil-empresarial, é vedada a desconsideração da personalidade
jurídica fundada unicamente na dissolução irregular da empresa, devendo haver elementos que
atestem o abuso da personalidade configurado pelo desvio de finalidade ou confusão
patrimonial, nos termos do art. 50 do CC/2002." (STJ, $4^{\mathrm{a}}$ T., Ag. no Resp. 347.476 - DF, re. Min.
Raul Araújo, j. 5/5/2016) - grifo nosso.
}

Portanto, a situação de irregularidade da sociedade não deve ser entendida, por si só, como fundamento para a desconsideração da personalidade jurídica. Mesmo porque, se a sociedade está irregular, 
haverá a responsabilização ilimitada dos sócios da sociedade, ante a despersonificação desta, em razão de sua irregularidade:

"EXECUÇÃO. DESCONSIDERAÇÃO DA PERSONALIDADE JURÍDICA. Embora não preenchidos os requisitos do artigo 50, do Código Civil, restou configurado o encerramento irregular da empresa devedora [...] Possibilidade de inclusão dos sócios no polo passivo, em razão da responsabilidade solidária e ilimitada, como já previa o artigo 10 do Decreto $n .^{\circ} 3.708 / 19$, reiterado pelo artigo 1.080 do Código Civil.” (TJSP, AI n. 0028934-17.2013.8.26.000, j. 5/6/2013) grifo nosso.

Há autores, inclusive, que defendem que tendo em vista que a sociedade em comum é despersonificada, a "consequência da falta de personalidade jurídica [...] deveria acarretar, em tese, a responsabilidade ilimitada e direta dos seus sócios pelas obrigações sociais" (RAMOS, 2012, p. 228), em que pese o Código Civil ter definido que a responsabilidade é ilimitada, mas subsidiária, definindo a responsabilidade ilimitada e direta "somente do sócio que contratou pela sociedade" (RAMOS, 2012, p. 228).

Nesse ponto, mister notar a diferença entre a despersonificação - que pode ser resumida na ausência de personalidade -, e a desconsideração, que se alinha ao afastamento momentâneo da personalidade, que, por óbvio, existe - para poder ser afastada -, e continua existindo após a aplicação da desconsideração. Nesse sentido, veja-se:

\begin{abstract}
"A desconsideração da personalidade jurídica não visa à sua anulação, mas somente objetiva desconsiderar, no caso concreto, dentro de seus limites, a pessoa jurídica, em relação às pessoas ou bens que atrás dela se escondem, com a declaração de sua ineficácia para determinados efeitos, prosseguindo, todavia, incólume para seus outros fins legítimos.” (STJ, 4ª T., Resp. 1.729.554/SP, Rel. Min. Luis Felipe Salomão, j. 8/5/2018, Dje 6/6/2018) - grifo nosso.
\end{abstract}

Não obstante, diversos julgados vinculam desconsideração e despersonificação, ainda que sutilmente, em que se nota uma indesejável confusão entre os temas, indicando que a dissolução irregular autorizaria a desconsideração da personalidade jurídica:

"Do encerramento irregular da empresa presume-se o abuso da personalidade jurídica, seja pelo desvio de finalidade, seja pela confusão patrimonial, apto a embasar o deferimento da desconsideração da personalidade jurídica da empresa, para se buscar o patrimônio individual de seu sócio" (STJ, 3ª T., REsp 1259066/SP, Rel. Min. Nancy Andrighi, DJe 28/6/2012) - grifo nosso.

"A desconsideração da personalidade jurídica, com a consequente invasão no patrimônio dos sócios para fins de satisfação de débitos da empresa, é medida de caráter excepcional sendo apenas admitida em caso de evidente caracterização de desvio de finalidade, confusão patrimonial ou, ainda, conforme reconhecido por esta Corte Superior, nas hipóteses de dissolução irregular sem a devida baixa na junta comercial" (Precedentes: REsp 1.169.175/DF, Rel. Ministro Massami Uyeda, Terceira Turma, julgado em 17/2/2011, DJe 4/4/2011; AgRg no Ag 867.798/DF, Rel. Ministro Luis Felipe Salomão, Quarta Turma, julgado em 21/10/2010, DJe 3/11/2010) - grifo nosso. 
O alerta de que não se trata de anular a personalidade jurídica já era feito há décadas por Requião, mas ainda se mostra oportuno, tal como destacado pelo Ministro Luis Felipe Salomão, do STJ, em recente julgamento do REsp n. 1.729.554/SP:

\begin{abstract}
"Esta é a doutrina de Rubens Requião sobre a natureza jurídica da desconsideração:
(...) a disregard doctrine não visa anular a personalidade jurídica, mas somente objetiva desconsiderar, no caso concreto, dentro de seus limites, a pessoa jurídica, em relação às pessoas ou bens que atrás dela se escondem. É o caso de declaração de ineficácia especial da personalidade jurídica para determinados efeitos, prosseguindo, todavia, a mesma incólume para seus outros fins legítimos. (Abuso de direito e fraude através da personalidade jurídica. Revista dos Tribunais. São Paulo: RT, v. 410, dez., 1969, p. 14)." (STJ, 4a T., Resp. 1.729.554/SP, Rel. Min. Luis Felipe Salomão, j. 8/5/2018, Dje 6/6/2018) - grifo nosso.
\end{abstract}

Em síntese, na desconsideração “atinge-se a separação patrimonial no plano da eficácia, não a sociedade no plano da existência" (SZTAJN, 1999, p. 81/97), o que a diferencia, pois, da dissolução ou extinção da sociedade, que visam extinguir a personalidade jurídica.

Afinal, pode-se entender a dissolução como sendo "a primeira fase do processo de desaparecimento de uma sociedade empresária, significando que a sociedade parou de funcionar, deixou de exercer sua atividade. Porém, não perdeu, ainda, sua personalidade jurídica." (ROCHA; ROCHA FILHO, 2018, p. 483). Apesar de, nesse momento de dissolução, a sociedade ainda permanecer existindo, com sua personalidade jurídica, ela não deve continuar exercendo sua atividade, vez que deve ser dada continuidade ao processo de extinção dela, iniciado pela dissolução, para que sejam ultimados seus negócios, visando à sua liquidação e extinção. Cumpridos esses passos, a sociedade deixará de existir efetivamente, e será extinta sua personalidade jurídica.

\title{
2.3 A desconsideração da personalidade jurídica $x$ responsabilização de administrador
}

A desconsideração também não se confunde com a eventual responsabilização de administrador, que age com culpa ou dolo nas suas funções, pois esse tema é interna corporis. O art. 158, da Lei n. 6.404/1976, das sociedades por ações ${ }^{12}$, prevê tal responsabilidade, de forma de devemos ter em mente os deveres previstos nos arts. 153 a 157, da referida lei, a saber: observar os limites da Lei e do estatuto; diligência; lealdade; não agir em conflito de interesses; informação. Em outra publicação, exemplificamos:

"Uma conduta prática que pode exemplificar a violação desses deveres pelo administrador, especialmente o de lealdade, é a prática de insider trading, que pode ser definido como o

\footnotetext{
${ }^{12}$ Art. 158. O administrador não é pessoalmente responsável pelas obrigações que contrair em nome da sociedade e em virtude de ato regular de gestão; responde, porém, civilmente, pelos prejuízos que causar, quando proceder:

I - dentro de suas atribuições ou poderes, com culpa ou dolo;

II - com violação da lei ou do estatuto.
} 
aproveitamento e uso, pelo administrador, de informação restrita e relevante sobre o estado e os negócios da sociedade, a que teve acesso em razão de seu cargo, para negociar valores mobiliários emitidos pela sociedade que administra, antes da divulgação dessa informação aos acionistas, investidores ou operadores do mercado, evidenciando um privilégio indevido.” (ROCHA; ROCHA FILHO, 2018, p. 443).

Apesar de o resultado buscado não vincular o administrador - vez que sua obrigação é de meio e, não, de fim -, ele responderá, civilmente, pelos prejuízos que eventualmente causar, quando agir com culpa ou dolo, dentro de suas atribuições ou poderes, tendo responsabilidade (interna corporis) perante a sociedade por ele administrada. Nesse caso, será cabível ação de responsabilidade da companhia contra o administrador, nos termos do art. 159 , da Lei n. $6.404 / 76^{13}$, sem se falar em desconsideração da personalidade jurídica, portanto.

\title{
2.4 A desconsideração da personalidade jurídica $x$ insolvência ou ausência de bens do devedor
}

Nesse ponto, interessante notar que, apesar de o tema ser frequentemente relacionado à inexistência de bens do devedor, ou à sua insolvência, isso não é requisito legal, tanto que parte da doutrina (RAMOS, 2012, p. 414) alerta expressamente sobre isso, defendendo a desnecessidade de comprovação de insuficiência patrimonial da pessoa jurídica, para autorizar a desconsideração - com o que estamos de acordo -, e conforme já decidido pelo Superior Tribunal de Justiça:

\begin{abstract}
"A mera demonstração de inexistência de patrimônio da pessoa jurídica ou de dissolução irregular da empresa sem a devida baixa na Junta Comercial, por si sós, não ensejam a desconsideração da personalidade jurídica" (STJ, 4ª T., Ag. no Resp. 347.476 - DF, Rel. Min. Raul Araújo, j. 5/5/2016) - grifo nosso.
\end{abstract}

“[...] a existência de bens penhoráveis não é causa para se afastar, por si só, a aplicação do instituto, porquanto a desconsideração da personalidade jurídica pode ser decretada por causas não relacionadas ao patrimônio da sociedade. (STJ, 4 ${ }^{\mathrm{a}}$ T., Ag. em Resp. 687.293/SP, Rel. Min. Maria Isabel Gallotti, j. 4/10/2018, Dje 23/10/2018) - grifo nosso.

\footnotetext{
${ }^{13}$ L. n. 6.404/76, art. 159: “Art. 159. Compete à companhia, mediante prévia deliberação da assembleia-geral, a ação de responsabilidade civil contra o administrador, pelos prejuízos causados ao seu patrimônio.

$\S 1^{\circ} \mathrm{A}$ deliberação poderá ser tomada em assembleia-geral ordinária e, se prevista na ordem do dia, ou for consequência direta de assunto nela incluído, em assembleia-geral extraordinária.

$\S 2^{\circ} \mathrm{O}$ administrador ou administradores contra os quais deva ser proposta ação ficarão impedidos e deverão ser substituídos na mesma assembleia.

$\S 3^{\circ}$ Qualquer acionista poderá promover a ação, se não for proposta no prazo de 3 (três) meses da deliberação da assembleiageral.

$\S 4^{\circ}$ Se a assembleia deliberar não promover a ação, poderá ela ser proposta por acionistas que representem 5\% (cinco por cento), pelo menos, do capital social.

$\S 5^{\circ}$ Os resultados da ação promovida por acionista deferem-se à companhia, mas esta deverá indenizá-lo, até o limite daqueles resultados, de todas as despesas em que tiver incorrido, inclusive correção monetária e juros dos dispêndios realizados.

$\S 6^{\circ} \mathrm{O}$ juiz poderá reconhecer a exclusão da responsabilidade do administrador, se convencido de que este agiu de boa-fé e visando ao interesse da companhia.

$\S 7^{\circ} \mathrm{A}$ ação prevista neste artigo não exclui a que couber ao acionista ou terceiro diretamente prejudicado por ato de administrador.
} 


\begin{abstract}
"A inexistência ou não localização de bens da pessoa jurídica não é condição para a instauração do procedimento que objetiva a desconsideração, por não ser sequer requisito para aquela declaração, já que imprescindível a demonstração específica da prática objetiva de desvio de finalidade ou de confusão patrimonial." (STJ, 4a T., Resp. 1.729.554/SP, Rel. Min. Luis Felipe Salomão, j. 8/5/2018, Dje 6/6/2018) - grifo nosso.
\end{abstract}

Por todo o exposto, vê-se que a insolvência, por si só, não deve ser considerada causa para a aplicação da desconsideração, mesmo porque a desconsideração da personalidade jurídica independe de prova da insolvência, pois o que deve ser apurado e provado é o desvio de finalidade ou a confusão patrimonial, caracterizadores do abuso de personalidade. Da mesma maneira, isoladamente, a constatação de insuficiência de patrimônio da sociedade - desacompanhada de prova de prática de ato abusivo ou fraudulento - não deve autorizar a desconsideração da personalidade jurídica.

\title{
3 DA ADEQUADA APLICAÇÃO DO INSTITUTO
}

A partir das ressalvas e diferenciações feitas anteriormente, nota-se a necessidade de os magistrados estarem atentos para não aplicar, indiscriminadamente e sem rigor técnico, a teoria da desconsideração da personalidade jurídica. Afinal, conforme exposto alhures, amiúde recorre-se à desconsideração desnecessariamente, pois as soluções mais apropriadas seriam relacionadas à responsabilização ilimitada já existente, em razão do tipo societário, da irregularidade do exercício da atividade econômica, ou à responsabilização pessoal dos administradores por ato contrário à Lei, ao contrato ou ao estatuto. Afinal, a desconsideração da personalidade jurídica não deve ser confundida com a responsabilidade ilimitada que recai, automaticamente, sobre um sócio (sociedade em nome coletivo, sociedade em comum, de fato ou irregular), nem com as situações que autorizem a responsabilização pessoal dos administradores, conforme disposto no art. 158, da Lei n. 6.404/76 ${ }^{14}$.

Abaixo, um caso em que consideramos adequada a aplicação da desconsideração da personalidade jurídica:

\footnotetext{
“AGRAVO INTERNO NO AGRAVO EM RECURSO ESPECIAL. EXECUÇÃO. DESCONSIDERAÇÃO DA PERSONALIDADE JURÍDICA. POSSIBILIDADE. REVISÃO. SÚMULA 7/STJ. AGRAVO NÃO PROVIDO. 1. O Tribunal de origem, analisando pormenorizadamente a prova dos autos concluiu por manter a desconsideração da personalidade jurídica para atingir as empresas ora recorrentes uma vez que assentou haver farta comprovação de abuso de personalidade jurídica em razão do desvio de finalidade e confusão patrimonial, na forma do art. 50 do Código Civil, assim como a reiterada obstaculização, pela executada, ao cumprimento da decisão condenatória por meio da blindagem da personalidade jurídica. 2. Dessa forma, observa-

${ }^{14}$ L. n. 6.404/76, art. 158. "O administrador não é pessoalmente responsável pelas obrigações que contrair em nome da sociedade e em virtude de ato regular de gestão; responde, porém, civilmente, pelos prejuízos que causar, quando proceder:

I - dentro de suas atribuições ou poderes, com culpa ou dolo;

II - com violação da lei ou do estatuto."
} 
se que o Tribunal de origem analisou a prova dos autos para concluir acerca da intrínseca relação entre as empresas, caracterizada pelos sócios, diretores e procuradores em comum, bem como mesmas atividades a se caracterizarem como componentes de um grupo econômico familiar, com desvio de finalidade e confusão patrimonial para o mau uso das empresas criadas. 3. Nesse contexto, o acolhimento da pretensão recursal exigiria a alteração das premissas fático-probatórias estabelecidas pelo acórdão recorrido, com o revolvimento das provas carreadas aos autos, atraindo o óbice da Súmula 7 do STJ. 4. Agravo interno não provido." (STJ, 4 ${ }^{\mathrm{a}}$ T., AgInt no AgInt nos EDcl no AREsp n. 983.360/PR, Rel. Min. Luis Felipe Salomão, j. 10/10/2017, DJe 13/10/2017) - grifo nosso.

Apesar de o objetivo deste trabalho ser uma análise material, vale registrar que a partir da vigência da Lei n. 13.105/2015 (Novo Código de Processo Civil), com a normatização do Incidente de Desconsideração da Personalidade Jurídica, regulado nos arts. 133 ao 137, a normatizar os aspectos processuais de tal medida, é possível que tal regramento contribua para uma adoção e aplicação mais criteriosa, pois com essas novas regras, o Brasil passa a contar com normas procedimentais mais específicas para a desconsideração da personalidade jurídica.

Seguindo esse raciocínio, é sempre oportuno ter em mente que a aplicação do referido instituto não deve ser entendida como ato arbitrário do juiz, vez que devem ser observadas as formalidades legais para sua adequada adoção, sob pena do uso indiscriminado tornar-se regra e, consequentemente, tornar-se um grande obstáculo ao empreendedorismo, especialmente quando se está diante de relações consumeristas, por exemplo, em que é possível a aplicação do disposto no art. $28, \S 5^{\circ}$, do Código de Defes a do Consumidor (Lei n. 8.078/90) ${ }^{15}$. Sobre isso, Chagas faz importante alerta sobre tal dispositivo:

“[...] sua redação chega a ser um obstáculo ao empreendedorismo, pois o legislador estabeleceu que os sócios sejam atingidos em seu patrimônio, 'sempre que, de alguma forma', houver dano causado ao consumidor. A regra é precipitada, assustadora e exterminadora da possibilidade de se exercer a atividade econômica com a segurança decorrente da proteção do patrimônio pessoal. [...]

Proteger o consumidor é necessário, todavia também é necessário garantir a atividade produtiva, estimulá-la e protegê-la, pois a todos (Estado, Mercado, Empregados, Consumidores, Coletividade) interessam a constituição e a preservação das pessoas jurídicas produtivas." (CHAGAS, 2016, p. 347/348).

Destacamos, a seguir, julgado em que várias das questões tratadas até aqui são sintetizadas na ementa:

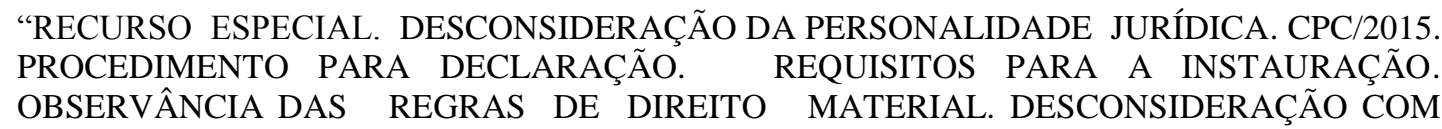

${ }^{15}$ L. n. 8.078/90, art. 28: “O juiz poderá desconsiderar a personalidade jurídica da sociedade quando, em detrimento do consumidor, houver abuso de direito, excesso de poder, infração da lei, fato ou ato ilícito ou violação dos estatutos ou contrato social. A desconsideração também será efetivada quando houver falência, estado de insolvência, encerramento ou inatividade da pessoa jurídica provocados por má administração.

Omissis.

$\S 5^{\circ}$ Também poderá ser desconsiderada a pessoa jurídica sempre que sua personalidade for, de alguma forma, obstáculo ao ressarcimento de prejuízos causados aos consumidores. 
BASE NO ART. 50 DO CC/2002. ABUSO DA PERSONALIDADE JURÍDICA. DESVIO DE FINALIDADE. CONFUSÃO PATRIMONIAL. INSOLVÊNCIA DO DEVEDOR. DESNECESSIDADE DE SUA COMPROVAÇÃO. 1. A desconsideração da personalidade jurídica não visa à sua anulação, mas somente objetiva desconsiderar, no caso concreto, dentro de seus limites, a pessoa jurídica, em relação às pessoas ou bens que atrás dela se escondem, com a declaração de sua ineficácia para determinados efeitos, prosseguindo, todavia, incólume para seus outros fins legítimos. 2. O CPC/2015 inovou no assunto prevendo e regulamentando procedimento próprio para a operacionalização do instituto de inquestionável relevância social e instrumental, que colabora com a recuperação de crédito, combate à fraude, fortalecendo a segurança do mercado, em razão do acréscimo de garantias aos credores, apresentando como modalidade de intervenção de terceiros (arts. 133 a 137) 3. Nos termos do novo regramento, o pedido de desconsideração não inaugura ação autônoma, mas se instaura incidentalmente, podendo ter início nas fases de conhecimento, cumprimento de sentença e executiva, opção, inclusive, há muito admitida pela jurisprudência, tendo a normatização empreendida pelo novo diploma o mérito de revestir de segurança jurídica a questão. 4. Os pressupostos da desconsideração da personalidade jurídica continuam a ser estabelecidos por normas de direito material, cuidando o diploma processual tão somente da disciplina do procedimento. Assim, os requisitos da desconsideração variarão de acordo com a natureza da causa, seguindo-se, entretanto, em todos os casos, o rito procedimental proposto pelo diploma processual. 6. Nas causas em que a relação jurídica subjacente ao processo for cívelempresarial, a desconsideração da personalidade da pessoa jurídica será regulada pelo art. 50 do Código Civil, nos casos de abuso da personalidade jurídica, caracterizado pelo desvio de finalidade, ou pela confusão patrimonial. 7. A inexistência ou não localização de bens da pessoa jurídica não é condição para a instauração do procedimento que objetiva a desconsideração, por não ser sequer requisito para aquela declaração, já que imprescindível a demonstração específica da prática objetiva de desvio de finalidade ou de confusão patrimonial. 8. Recurso especial provido." (STJ, 4 Turma, REsp 1729554/SP, rel. Min. Luis Felipe Salomão, j. 8/5/2018, DJe 6/6/2018) - grfio nosso.

Chagas explica que o disposto no art. 50, do Código Civil - em consonância com a obra de Rolf Serick -, possibilita a mitigação dos efeitos decorrentes da personificação, em situações em que seja identificável o "uso indevido do ente coletivo ou a negação do princípio da autonomia patrimonial", momento em que seria "não identificável uma linha divisória entre o patrimônio particular dos sócios e o patrimônio da sociedade" (CHAGAS, 2016, p. 343).

Nesse ponto, oportuna a relação da desconsideração da personalidade jurídica com a intencional subcapitalização societária pelos sócios. Albergaria Neto e Cateb ensinam que poder-se entender a subcapitalização societária como "fruto do descompasso contábil entre o passivo e o ativo", sendo visível quando "o capital social não é proporcional ao objeto social", situação que revelaria "desobediência ao princípio da adequação do capital social" (ALBERGARIA NETO; CATEB, 2017, 503-518), informação que deve ser de conhecimento dos sócios, para que seja retificada, sob pena de - caso os sócios permaneçam inertes - tal conduta autorizar a desconsideração, ensejando a responsabilidade dos sócios

Nesse sentido, Barbosa explica que tal ato poderia ser uma manobra fraudulenta "por vias transversas ou menos aparentes" (BARBOSA, 2017, p. 51-96). Esse raciocínio possibilitaria a aplicação do instituto - desconsideração -, em variadas situações em que se configure a intencional subcapitalização societária pelos sócios. A dificuldade poderá se revelar na prática, amiúde, pela forma subrepitícia dessa subcapitalização, o que demandaria a fixação de parâmetros do que se entende, no caso 
concreto, como sendo uma adequada capitalização societária, tanto sob a ótica contábil, como também sob a ótica do mercado em que a pessoa jurídica atua.

Mas, independentemente do critério, frisa-se que isso não é sinônimo de comprovação da insolvência jurídica, por ser, em verdade, "manifesta incongruência entre o capital social e o objeto social" (ALBERGARIA NETO; CATEB, 2017, 503-518), fato determinante para se afastar a autonomia patrimonial da sociedade, que poderia ser confirmado por alguns outros aspectos, tal como indicado por Diniz, a saber: adoção de um "tipo societário com limitação de responsabilidade", ausência de capitais próprios "suficientes para financiamento das necessidades da atividade", "utilização de capitais de terceiros em desequilíbrio com capitais próprios" (DINIZ, 2012, p. 182). Isso, porque, quanto ao primeiro aspecto, deve-se ter em conta que o tipo societário que gera responsabilidade limitada aos sócios - tais como a sociedade limitada e a anônima -, é o que enseja a separação patrimonial da sociedade e dos sócios, o que é necessário para se cogitar a desconsideração, conforme exposto anteriormente; no tocante ao segundo aspecto, a ausência de capitais próprios, para custeio da empresa poderia denotar desequilíbrio financeiro, com iminente risco de perda do crédito; assim, como o terceiro aspecto, pois a exagerada necessidade de recursos de terceiros poderá ocasionar desequilíbrios com o capital próprio, vez que a necessidade de remuneração e devolução dos valores a terceiros pode impor endividamentos.

Ainda sobre a questão do capital próprio, é preciso ter em mente que a constituição da sociedade pressupõe reunião de recursos que formarão seu capital social, mas que, embora seja essencial nesse momento, não se limita unicamente ao nascimento da sociedade. Barbi explica:

\footnotetext{
"Em verdade, o capital social constitui a medida da contribuição dos sócios para o fundo social, seja contemporânea ou superveniente à sua constituição, em troca de quotas de participação no empreendimento, com função de promover o melhor desenvolvimento dos negócios sociais. Seus efeitos, de ordens absolutamente distintas, serão o de servir de parâmetro à medida do desempenho econômico e, eventualmente, regular as relações internas de poder da sociedade." (BARBI, 2007, p. 7/8)
}

A ideia é que a pessoa jurídica seja a proprietária de todo o seu patrimônio, incluído o capital social, vez que a autonomia patrimonial é um atributo da personalidade. Dessa forma, no momento da integralização das quotas ou ações pelo sócio, “- seja em dinheiro elou outros bens, móveis, imóveis ou semoventes, corpóreos ou incorpóreos -, transfere, via de regra, tais bens à propriedade da sociedade" (ROCHA; ROCHA FILHO, 2018, p. 393). Mas, também tendo claro que o natural é que o capital social coincida com o patrimônio ou fundo social somente na constituição da sociedade - vez que capital social é um instrumento formal, e que o patrimônio é formado pelos direitos e bens da sociedade - , a tendência é que o capital social e o patrimônio não se equivalham, com o passar do tempo (BARBI, 2007, p. 8/9). E isso, frequentemente, não será indício de subcapitalização. 
Porém, interessante notar as seguintes situações: no momento da constituição da sociedade, os sócios, ao invés de promoverem uma adequada subscrição e integralização do capital social, tendo em vista o objeto da sociedade, preferem indicar um inadequado capital social nominal no ato constitutivo. Trata-se de medida comum no cotidiano societário a fixação de capital social quase módico, se comparado ao ramo de atividade e ao objeto desenvolvido. Haveria, nessa situação - capital social nominal irrisório -, ampliação do risco dos eventuais credores, quanto ao recebimento de seus créditos?

Ainda que não tenha sido definido o capital social módico no ato constitutivo, ao longo da vida da pessoa jurídica podem surgir situações que justifiquem o aumento do capital social - o que pode ser feito a qualquer tempo pelos sócios, para "financiamento da sociedade; adequação às necessidades do mercado, para participar de licitações, etc." (ROCHA; ROCHA FILHO, 2018, p. 395). Mas, nesse caso, os sócios decidem transferir em favor da sociedade os recursos de que ela necessita, mas tão somente a título de empréstimos a ela, de forma que tais valores não serão considerados patrimônio da pessoa jurídica. Isso evidenciaria se a pessoa jurídica utiliza recursos próprios no desenvolvimento de sua empresa, tendo patrimônio real, ou se depende muito de recursos alheios, tal como proposto acima. Haveria, nessa situação, - forte dependência de recursos de terceiros -ampliação do risco dos eventuais credores, quanto ao recebimento de seus créditos?

Entendemos que ambas implicam aumento do risco dos eventuais credores, quanto ao recebimento de seus créditos, o que poderia autorizar a aplicação da desconsideração, por vincular-se à fraude e/ou ao abuso da personalidade jurídica. Mas, mesmo nesses casos, é preciso cuidado, pois é certo que, inicialmente, o capital social nominal pode ser modesto, da mesma forma que se pode lançar mão, oportuna e adequadamente, de capital de terceiros, para acelerar os negócios, sem que isso seja indício de fraude, confusão patrimonial, nem leve, necessariamente, ao superendividamento.

Finalmente, mister notar que os efeitos da desconsideração, uma vez deferidos, não devem recair indiscriminadamente sobre os sócios e/ou administradores da sociedade, mas apenas sobre quem participou e/ou se beneficiou do uso abusivo da personalidade jurídica. Ramos exemplifica:

“[...] verificada a confusão patrimonial entre a sociedade e um de seus sócios, no nome de quem estão registrados veículos usados na atividade da sociedade, a decretação da desconsideração da pessoa jurídica deve atingir apenas esse sócio, fazendo a execução recair apenas sobre aqueles bens que caracterizam a confusão patrimonial (no caso, os veículos).” (RAMOS, 2012, p. 410).

As novas regras formais sobre o tema, reguladas no CPC de 2015, podem favorecer o aprimoramento e o uso racional do instituto, e, em que pese o receio de que possa mostrar-se mais lento, em razão das formalidades criadas, em verdade evitará práticas diversas quanto ao instituto da desconsideração, o que, amiúde, implicava atrasos processuais e, quiçá, insegurança jurídica, pois o uso 
da desconsideração de forma indiscriminada, sem critérios objetivos, "faz com que nos dias atuais exista uma crise da personalidade jurídica das sociedades empresárias, trazendo uma insegurança aos sócios" (ALBERGARIA NETO; CATEB, 2017, 503-518), e aumentando, desnecessariamente, os riscos da atividades empresarial.

\section{CONCLUSÃO}

Ao longo deste trabalho, evidenciou-se que, no aspecto material, a desconsideração da personalidade jurídica - que visa tornar possível o superamento, pelo juiz, da personalidade jurídica, para, pontual e episodicamente, combater a fraude ou o abuso cometidos por um dos sócios ou pelos sócios, valendo-se da pessoa jurídica -, é medida valiosa e se mostra oportuna quando o sócio ou os sócios se valem da pessoa jurídica como escudo para cometer fraudes ou abusos.

Em que pese o valor desse instituto para os credores, não se pode olvidar que se trata de medida aguda, que deve, pois, ser utilizada com bastante critério, para que sua aplicação seja oportuna, o que ocorrerá quando presente o abuso sustentado em dolo, fraude, desvio de finalidade ou confusão patrimonial, com a finalidade de prejudicar terceiros. E isso, não necessariamente, implicará a responsabilização dos sócios pela simples dissolução da sociedade, ou pela insolvência ou inexistência de bens do devedor, muito menos em casos de responsabilização de administrador, nem responsabilização de sócio em sociedade de responsabilidade ilimitada. É preciso ter isso claro, pois o uso adequado da desconsideração da personalidade jurídica favorecerá a segurança jurídica, contribuindo, por esse caminho, para o respeito à norma casuisticamente.

\section{REFERÊNCIAS}

ALBERGARIA NETO, Jason Soares de; CATEB, Alexandre. A subcapitalização como critério para desconsideração da personalidade jurídica. P. 503-518. In: CAD 20 anos: tendências contemporâneas do Direito. AMARAL, Paulo Adyr Dias do; RODRIGUES, Raphael Silva (Coords.). Belo Horizonte: D’Plácido, 2017.

BARBOSA, Henrique Cunha. Usos e desusos do incidente de desconsideração da personalidade jurídica. In: Os impactos do novo CPC no direito empresarial. Orgs. PERRUCI, Felipe Falcone; MAIA, Felipe Fernandes Ribeiro; LEROY, Guilherme Costa. Belo Horizonte: D’Plácido, 2017, p. 51-96.

BORBA, José Edwaldo Tavares. Direito societário. 12 ed. rev., aum. e atual. Rio de Janeiro: Renovar.

CHAGAS, Edilson Enedino das. Direito empresarial esquematizado. Coord. Pedro Lenza. 3 ed., São Paulo: Saraiva, 2016. 
DINIZ, Gustavo Saad. Subcapitalização societária: financiamento e responsabilidade. Belo Horizonte: Fórum, 2012.

OLIVEIRA, Júlio Moraes. Curso de direito do consumidor completo. Belo Horizonte: D’Plácido, 2014.

RAMOS, André Luiz Santa Cruz. Direito Empresarial esquematizado. 2 ed. rev., atual. e ampl.. Rio de Janeiro: Forense, 2012.

ROCHA, Gustavo Ribeiro; ROCHA FILHO, José Maria. Curso de Direito Comercial - teoria geral da empresa, direito societário, títulos de crédito, falência e recuperação de empresas. 5 ed., Belo Horizonte: D’Plácido, 2018.

SZTAJN, Rachel. Sobre a desconsideração da personalidade jurídica. São Paulo: Revista dos Tribunais, n. 88 , v. 762 , p. $81 / 97,1999$. 